
$\angle$ Research Square
Preprints are preliminary reports that have not undergone peer review.
They should not be considered conclusive, used to inform clinical practice, or referenced by the media as validated information.

\title{
In Vivo Antidepressant Efficacy of 3-substituted Thietane-1, 1-dioxide Derivative - A Preliminary Study for Novel Anti-depression Therapy in Neurological Disorders
}

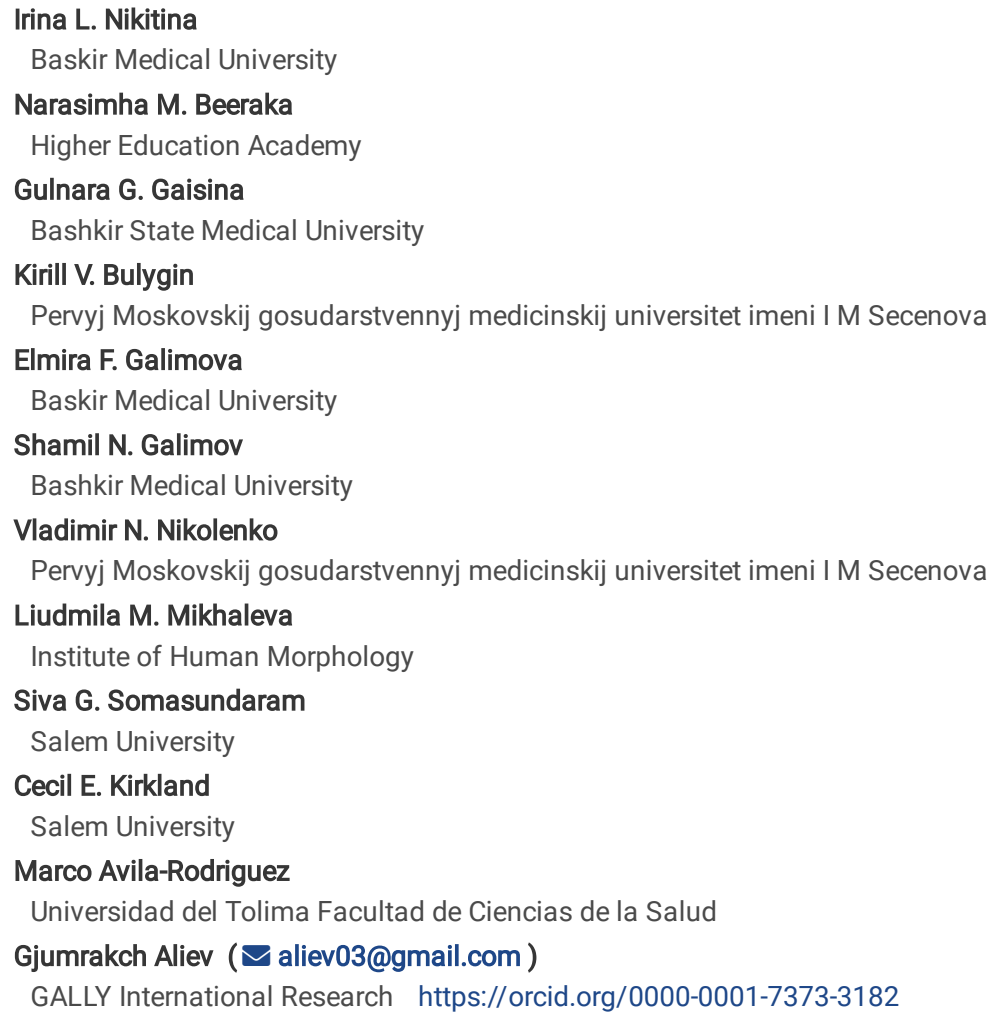

Research

Keywords: resident-intruder test, CMSS, 3-substituted thietane-1,1-dioxide, antidepressant, SD rats, aggression

Posted Date: June 11th, 2020

DOI: https://doi.org/10.21203/rs.3.rs-34213/v1

License: (9) (7) This work is licensed under a Creative Commons Attribution 4.0 International License. Read Full License 


\section{Abstract}

Background: Psychosocial stress-induced depressive behavior is linked to etiology of several neurological diseases viz., PTSD, and neurodegenerative disease like Alzheimer's disease (AD). The repeated bouts of social stress defeat can be induced using Resident-Intruder-Paradigm (RIP) and chronic mild social stress (CMSS) animal models to assess the stress-induced depressive behavioral patterns. The aim of this study to examine the anti-depressive efficacy of 3 methoxythietane-1,1-dioxide (N-14) in RIP models of behavioral alterations.

Methods: In this study, we have used Sprague-Dawley rats in Resident-Intruder-Paradigm (RIP), where intruders interacted with residents Day 0 to Day +5 for 10 minutes to invoke CMSS in intruders and became defeated/submissive rats due to the depressive-like behavioral alterations in social activity, explorations, grooming, defense, aggressive behavior, and social interaction, freeze, and rearing etc., with residents. Group I is control intact animals, group II received N-14 alone; group III received CMSS, and group IV received cotreatment of N14 with CMSS. N-14 (2 mg/kg) was administered intraperitoneally from Day 0 to Day +5 to intact animals and intruder animals under conditions of CMSS. Several behavioral tests viz., forced swim test, open field test, and elevated-plus maze test were used to examine the above behavioral dynamic parameters.

Results: the dynamic interaction between Residents and Intruders during the study showed substantial alterations in exploratory activity, aggressiveness, and defensive behavior, body weight, and thymus mass in stressed animals. N-14 cotreatment has mitigated sociability, exploratory activity, and aggressiveness and increased social adaptability and defensive behavior. Extensive rise in active forms of defense and submission latency indicate that $\mathrm{N}-14$ has induced antidepressant activity with a psycho-sedative component of action.

Conclusion: Serendipitously, we observed the ameliorative capability of $\mathrm{N}-14$ cotreatment to mitigate depressive-behavioral symptoms in intruders. Since it is a preliminary study, we have not examined any pathophysiological and molecular signaling to delineate the efficacy of $\mathrm{N}$ - 14 in retarding depressive-behavioral symptoms. Our future studies will address these aspects to fully consider N-14 as a novel therapy against stress-induced depression in neuropsychiatric and neurodegenerative disorders (ex. AD) using in vivo and clinical models.

\section{Background}

Alzheimer's disease is associated with dementia constituted by the cognitive decline and functional impairment of neuropsychiatric functions. This disorder currently affecting 5.6 million Americans aged 65 years and the figure is estimated to increase nearly 16 million by 2050 . The total payments in 2020 health care and long-term care for AD with comorbid depression patients for aged 65 years and older are estimated to be 305 billion USD

[doi.org/10.1002/alz.12068]. The comorbid neuropsychitatirc symptoms (NPS) associated with AD affects daily living, quality of life [1, 2]. In addition, these symptoms are leading to the accelerated disease progression, and mortality [3, 4].

Apathy and depression are the most common comorbid NPS in AD patients. Albeit, several geropsychiatric measures are abundant for diagnosis, the monitoring of depression in AD patients are still remain imperfect [5]. Several pharmacological and nonpharmaclogical interventions are used to treat depression in AD. Depression is the most common NPS in AD patients [5]. Depression induces mild cognitive impairment (MCl) events as studied from metaanalysis of 57 clinical studies; nearly prevalence of $32 \%$ in patients with $\mathrm{MCl}$ is associated with other depressive symptoms [5-12]. A plethora of studies from clinical setting reported the $\mathrm{MCl}$ in $\mathrm{AD}$ patients with a rapid, extensive cognitive decline than the non-depressed AD patients [13]. In addition, the beta-amyloid neuritic plaques \& neurofibrillary tangles in cerebral parenchyma, serotonin receptor loss, defects in frontal-striatal and frontal-limbic brain pathway are extensively found in $A D$ patients comorbid with $\mathrm{MCl}$ than non-depressed $A D$ patients [14-16]. A study reported that $16 \%$ of $A D$ patient exhibited depression in a population-based study whereas the $44 \%$ of AD patients have attained depression in a hospital-based study; these are indicating depression as an early manifestation of $A D[17,18]$.

Several risk factors were reported to develop depression during neurological diseases; mainly the risk factors viz., the familial history of depression, female sex, ApoE-4 positivity, and the usage of certain medications [19-21]. For instance, the intake of beta-adrenergic receptor blockers, corticosteroids, benzodiazepines, recurrent exposure to dopamine antagonists, statins, proton-pump inhibitors, anxiolytics, hormone-replacement therapies, anticonvulsants, and anticholinergic drugs like dicyclomine, and prolonged exposure to CNS stimulants are likely induces the depressive disorder in people exposing to prolonged chronic mild social stress, both depressed AD \& non-depressed AD patients, and stroke patients, and [5]. Thus, depression is a critical issue with both medically and socioeconomically implications [5].

Depression is accompanied by the social risk factors, diminished cooperativeness, and competition avoidance due to behavioral alterations. The chronic social stress like trauma, abuse, frequent illness, fear etc. will likely to enhance the depressive symptoms in patients with neurodegenerative diseases like AD [22]. In addition, the depression is also associated with the 'social anhedonia, hypersensitivity to social rejection, impaired social communication, impaired aggression, and impaired emotion recognition'. These kind of dysfunctional social processes in animal models of social stress are attributed to the behavioral, neuroanatomical, and genetic levels [22].

Antidepressants like tricyclic antidepressants such as amitryptiline, imipramine, selective serotonin reuptake inhibitors (SSRIs) such as fluoxetine, paroxetine etc., are preferred to treat major depressive symptoms viz., altered mood libidos, stress-induced behavioral alterations in neurodegenerative diseases (ex. AD), postpartum depression, and postschizophrenic depression etc., [23]. The moclobemide is ineffective in relieving symptoms of depression with no further improvement in cognitive function [24, 25]. Fluoxetine, sertaline, citalopram are normally prescribed for AD patients with depression. However, their usage is constrained by the additional comorbid cognitive decline, and nausea, vomiting, diarrhea, anorexia, weight loss, dizziness, constipation, and dry mouth, anxiety, and insomnia etc., Therefore, the selection of a particular antidepressant must encompass the adverse effects to treat comorbid symptoms such as behavioral alterations in depression [5,23]. However, therapeutic effectiveness of antidepressants varies by individual and may have serious behavioral abnormalities and other side-effects. Therefore, there is an urgent need for the development of new and more efficacious antidepressants [5]. Unfortunately, a

Page $2 / 16$ 
large proportion of promising molecules in preclinical studies have been shown to be ineffective in clinical trials stage. The actual consequences for clinical failure of several antidepressant molecules are associated to the lack of assessment of existing models of depressive-like states [5, 26, 27].

In addition, we have examined the safety profile and activity of new promising lead compounds from the 3-substituted thiethan-1,1-dioxides class (Ex., 3methoxyethane-1,1-dioxide, laboratory code $\mathrm{N}$-14). First time, we have examined the efficacy of heterocyclic compound $\mathrm{N}$ - 14 and there is no current literature available. N-14 showed antidepressant effects and low toxicity in the in vivo model $[28,29]$. Alternatively, the models based on "social stress \& residentintruder paradigm" are predictive and can be validated. These model methods are efficiently beneficial to invoke behavioral and homeostatic behaviors in animal models in a semi-natural environment. In addition, these methods significantly beneficial for examining the efficacy of antidepressants to reverse abnormal behaviors associated with depression [27]. We used modified RIP that enable the assessment of aggressive and defensive behaviors [30]. The present research is a 'preliminary study'to examine the psychopharmacology of "3-substituted thietane-1, 1-dioxide derivative ( $\mathrm{N}$-14)" in vivo models of invoking depression through social stress; this could be a 'prospective novel animal model' to determine the effects of stress on adolescent neurobehavioral phenomenon consequently beneficial to develop novel nontoxic therapeutic intervention against comorbid depression using in vivo models of neurodegenerative diseases including $A D$.

\section{Chemical Structure}

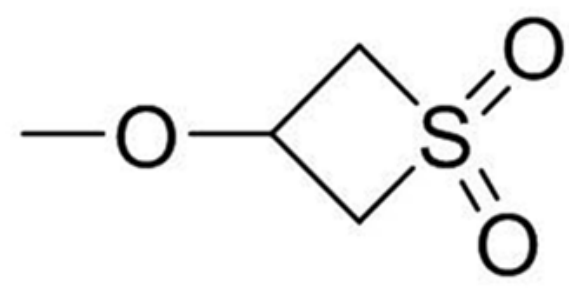

\section{Structure of N-14 (3-substituted thietane-1,1-dioxide derivative)}

\section{Methods \\ Experimental design}

Animals: All animal procedures were carried out in accordance with the International Recommendations of the European convention for the protection of vertebrate animals used for experimental and other scientific purposes [31]. These procedures were approved by the Ethical Committee for animal care of the Bashkir State Medical University, Ufa, Russian Federation. The experimental subjects were white male Sprague Dawley rats [32]. They were kept in standard vivarium conditions with a 12/12 h light/dark cycle (lights off at 20:00) and provided water and food ad libitum.

Before experiment, all male rats were categorized into "Residents" and "Intruders" [32]. Resident male rats weighing 250-350 g were housed in large individual cages $(90 * 60 * 50 \mathrm{~cm})$ for more than 2 weeks to facilitate the development of territoriality. Each male was provided a sterilized companion female one week before the test to enhance territoriality and prevent effects of social isolation. Two days before the test, Residents interacted with small non-experimental male rats for 10 minutes twice a day to develop dominance behavior.

Intruders were male rats of smaller size (150-250 g). They were randomly assigned to 4 experimental groups:

\section{Group I}

Intact animals (control)

\section{Group II}

Animals treated with $\mathrm{N}-14$ on Days from 0 to +5

\section{Group III}

Animals that underwent resident-intruder CMSS on Days 0 to +5

\section{Group IV}

Animals that underwent CMSS and received $\mathrm{N}-14$ on Days from 0 to +5 ; on +6 th day, animals were ethically sacrificed 


\begin{tabular}{|lll|}
\hline & No N-14 & Received N-14 \\
\hline No CMSS & Group I & Group II \\
\hline Received CMSS & Group III & Group IV \\
\hline
\end{tabular}

The idea of the experiment is to develop depressive-like symptoms in Intruders due to repeated bouts of social defeat incurred by chronic mild social stress (CMSS) during Resident-Intruder interactions and N-14 cotreatment used to reverse these symptoms.

\section{Drug administration}

LD-50 of N-14 was determined as per Ivanova, O.A., Nikitina, I.L et al (2011) [28]. N-14 was suspended in Tween 80 and dissolved in $0.9 \% \mathrm{NaCl}$ solution and prepared $2 \mathrm{mg} / \mathrm{kg}$ concentration. Rats were treated daily with $\mathrm{N}-14$ or saline intraperitoneally in a volume of $2 \mathrm{ml} / \mathrm{kg}$ on days from 0 to +5 .

\section{Procedures}

Chronic bouts of social defeat were induced in intruders from chronic mild stress (CMSS) when interacting with residents in the cage [32, 33]. Intruders interacted with Residents for 10 minutes daily for 6 days (i.e., from Days 0 through +5 ). Interactions occurred during the dark phase. Interactions between residents and intruders were recorded using a Panasonic V760 camera.

The behavior of the Intruders was analyzed by computing the duration of the patterns and types of behaviors using BrainTest 2.0 program [34]. Trained observers collected data on social behaviors as follows:

1. Latency of First Interaction

2. Latency of Submission

3. Social Exploration

4. Non-Social Exploration

5. Sitting

6. Social Interaction, operationally defined as the sum of the patterns Fight and Attack

7. Social Inactivity, operationally defined as the sum of the patterns Rearing, Recline Against Wall, and Moving

8. Grooming

9. Defense, operationally defined as the sum of the patterns Move Away, Flight, Submissive Posture, Freeze, and Defensive Upright Posture

On Day +5 , Intruders were tested using the Forced Swimming Test (FST) [35]. On Day +5 they were tested in the Open Field (OF) and Elevated-Plus Maze (EPM) tests [36].

\section{Forced Swimming Test (FST)}

A subset of intruder Sprague Dawley rats experiencing CMSS underwent FST to ascertain the depressive-like behavior; and later, to assess the N-14 efficacy to ameliorate the behavioral alterations [32]. FST is composed of two testing days (on Day +5, Day +6), only the time spent immobile on $2^{\text {nd }}$ day could be inferred as the behavioral indicator of despair whereby the expressing urge to escape from adverse stimuli diminished. Initially the rats after subjecting to CMSS were placed in the plastic cylinder $\left[r^{1 / 1} 30.5 \mathrm{~cm} ; \mathrm{h} 1 \frac{1}{4} 46.0 \mathrm{~cm}\right.$ ] composed of three liters of water and maintained them at room temperature for 15 minutes. Subsequently, the procedure was repeated again next day for 5 minutes. Here, immobility is referred as the time spent motionless on the water surface without any submerged limb movement in the water was recorded for every rat using Zeiss (ZSD-808) Stopwatches. Higher immobility was considered as the depressive-behavior, which can be ameliorated by the administration of anti-depressants [37]; Mean \pm SEM immobile time during Day 2 (in 5 min) was noted for all the intruders.

\section{Open Field (OF)}

Open field activity of intruders experiencing CMSS was recorded using Opto-Varimex-3 Activity Meter (Columbus Instruments, Columbus, OH, USA) coupled with a standard, open, Plexiglas arena. The animal movement was recorded using infrared sensors by placing them $3 \mathrm{~cm}$ above the floor as described by $W e i$ S et. al., (2014) [33]. Each rat was placed in the centers of apparatus prior to the testing consequently allowed it to explore for at least 3 minutes. At this time, the open-field activity was recorded and the other exploratory dynamics viz., rearing etc., were observed with care and quantified these parameters [33].

\section{Elevated Plus Maze (EPM) test}

EMP is composed of plus-shaped platform situated above $80 \mathrm{~cm}$ from the floor. It consists of two open arms (50×10 cm; $100 \mathrm{lux})$ and two closed arms $(50 \times 10 \times 40 \mathrm{~cm} ; 20$ lux). Intruder rats were placed across the center square towards the closed arm. The following parameters were recorded for 5 minutes EPM test using Plus-maze version 2.0, [38], Ernst Fricke software; For instance, the parameters are,

Page 4/16 
$\rightarrow$ time spent in open and closed arms

$\rightarrow$ number of entries into open and closed arms

$\rightarrow$ latency to enter an open arm

Additionally, the weight gain of and the amount of food consumed by Intruders (comparing Days -1 to +5 ) were measured and coded in terms of $100 \mathrm{~g}$ of animal weight. At the end of the experiment, the animals were euthanized ethically. To assess the anti-depressant effect of $\mathrm{N}$ - 14 against stress-induced behavioral alterations, we have analyzed several behavioral patterns like social inactivity, exploration, grooming, defensive behavior, and aggressive behavior. In addition, we have examined the masses of the liver, spleen, thymus, and adrenal glands were measured.

\section{Statistical Analysis}

Statistica 10.0 (StatSoft, USA) was used for data analysis. Descriptive statistics included the median (M) and interquartile range (IQR). Mann-Whitney test was used for pair-wise comparison of variables; Wilcoxon test was used for dependent samples analysis [39]. For all statistical analyses, the significance level was $\mathrm{p}=0.05$.

\section{Results}

\section{Resident-Intruder interaction}

\section{$\mathrm{N}-14$ cotreatment induced behavioral alterations related to Social Interaction, Social Exploration etc.,}

Social Interaction is associated with inclusive actions of Fight and Attack. N-14 cotreatment in Group IV significantly mitigated Social Interaction on Day + 2 $(p<0.05)$ when compared to Group III animals. The Attack pattern was reduced 4.1-15.8 times on all days of the experiment, with statistical significance on Day 0 compared to Group III.

When compared to Day 0, the level of Social Interaction was decreased due to decline in the Attack pattern with and without N-14. However, this decline was statistically insignificant. The level of aggressiveness was declined in Group IV received N-14 cotreatment compared to Group III (CMSS only). This kind of behavioral alteration in the Social Interaction of Intruders under CMSS indicates alleviation of aggressiveness.

Social Inactivity can also be determined through the behavioral alterations pertaining to the sum of Rearing, Recline Against Wall, and Moving. Social Inactivity was decreased with N-14 cotreatment in Groups IV on Days $+1,+2,+3(\mathrm{p}<0.05)$ compared to Group III; further social inactivity was associated with a reduction in the total duration of patterns Moving on Days $+1,+2,+3(p<0.05)$, Recline Against Wall on Day $+2(p<0.05)$, and Rearing on Days +2 and $+3(p$ $<0.05)$. However, $\mathrm{N}-14$ cotreatment reduced Social Inactivity on Days +3 and +5 also due to decrease in the total duration of patterns Moving and Recline against Wall compared with Day 0 (statistically insignificant). In Group III, Social Inactivity was increased on Days +2 and +3 but decreased on Day +5 (statistically insignificant). Such dynamics are due to changes in Moving $(164 \%$ on Day +2 and $189 \%$ on Day $+3, p<0.05)$ and Rearing $(39 \%$ on Day $+5, p=$ 0.173) when compared to Day 0. Finally, it can be deduced that the change in Social Inactivity indicates a decrease in exploratory activity of animals with $\mathrm{N}-14$ cotreatment. Our results significantly correlated with $\mathrm{N}-14$-induced mitigation in the Non-Social Exploration $(p<0.05)$ on Day +5 , which goes along with Social Inactivity.

\section{Grooming}

Grooming pattern was significantly modulated in Groups III and IV. This effect was evident on all experimental days in Group III where maximum values were observed on Days +1 and $+4, p=0.08$ and $p=0.075$ respectively. This total duration of pattern was declined significantly with $\mathrm{N}-14$ cotreatment in Group IV on Days $+1,+4$, and +5 when compared to Group III $(p<0.05$ on Day +3$)$.

\section{Social Exploration}

$\mathrm{N}-14$ cotreatment also reduced Social Exploration pattern on all days of the experiment when compared to Group III $(p<0.05$ on Days 0 and +3$)$.

\section{Latency of First Interaction}

Latency of First Interaction was increased in Groups III and IV when compared to Day 0 ( $p<0.05$ on Day +1 , Group III); N-14 cotreatment enhanced the pattern value in Group IV on Days + 1 (161\%), + 4 (340\%) and + 5 (225\%) when compared to Group III.

\section{Defense}

Defensive behavior was higher in the group of stressed animals cotreated with N-14 $(p<0.05$, only on Day +3$)$ than in Group III due to the Freeze pattern. Freeze was higher on all experimental days $(p<0.05$, only on Day +3$)$ compared to the stressed animals of Group III (the proportion was $87-94 \%$, Figure-3). Unidirectional patterns of Defense and Freeze behaviors were observed in N-14 cotreatment in Group IV; there was a general decrease in Defense and Freeze behaviors when compared with Day 0 on Days $+2,+4,+5$. The Defense behavior on Day +1 was affected by a significant decrease in Defensive Upright Posture with $\mathrm{N}-14$ cotreatment than Day 0.

In case of Group III stressed animals, there was a tendency to decrease in defensive behavior on all days; which might be due to reduction in the Submission Posture on Days $+1,+2,+3,+5$ (statistically insignificant) and Freeze on Day +4 . 
During the experiment, passive forms of defense viz., Freeze and Submissive Posture prevailed in the behavior structure of animals of both groups. This was caused by individual behavioral alterations of the Intruders rather than specific response to CMSS [40]. The largest proportion of passive defense in animals treated with N-14 was Freeze (87-94\%, Figure-3); and it was declined on Days + 4 and + 5 compared to the other days. In case of Group III, the passive defense was represented by both Freeze and Submissive Posture on Days +1 to +4 , with an extensive propensity for the use of Submissive Posture.

$\mathrm{N}-14$ cotreatment in Group IV induced a significant decrease in Move Away pattern on Days 0, +2 and +3 and defensive behavior of Intruders (1-2\%, in stressed animals - 9-15\%) compared to the Stress Group III. In addition, N-14 significantly reduced the Defensive Upright Posture on Days +1 ( $p<0.05)$, +4 and +5 when compared to Group III, which correlates with alleviation of aggressive behavior in N-14 cotreatment and reflects the development of "adaptive survival strategy".

At the same time, $\mathrm{N}-14$ cotreatment promoted extensive increase in the patterns of Defensive Upright Posture on Days +2 and +3 as compared to Day 0 (the reverse trend was observed in the control group); $\mathrm{N}-14$ also fostered the rise in Flight on Days from 0 to +3 compared with both Day 0 and Group III. This is indicating the $\mathrm{N}-14$ induced manifestation of the antidepressant effect.

\section{Latency of Submission}

The antidepressant activity of $\mathrm{N}-14$ was confirmed by an increase in the Latency of Submission when compared to Group III (1.5-10 times on Days +2 to +5$)$, and in the dynamics relative to Day $0(1.4-9$ times on Days $+1,+3,+4,+5, p<0.05)$, with the behavioral pattern reaching its maximum on Day $+5($ Me $=$ $488.3 \mathrm{~s})$.

The results of Resident-Intruder interaction are shown in Table-1. Additionally, we calculated the proportions of each pattern in the structure of Intruders behavior on Days 0 to +5 . They are given in Fig. 2-3. 


\begin{tabular}{|c|c|c|c|c|c|c|c|c|c|}
\hline \multirow{3}{*}{$\begin{array}{l}\text { Pattern / } \\
\text { Type of } \\
\text { behavior }\end{array}$} & \multicolumn{2}{|l|}{ Day 0} & \multicolumn{2}{|l|}{ Day +1} & \multicolumn{2}{|l|}{ Day +2} & \multicolumn{2}{|l|}{ Day +3} & \multirow{3}{*}{$\begin{array}{l}\text { Day }+4 \\
\text { Stress } \\
\text { (III) }\end{array}$} \\
\hline & \multirow{2}{*}{$\begin{array}{l}\text { Stress } \\
\text { (III) }\end{array}$} & $\begin{array}{l}\text { Stress + N- } \\
14\end{array}$ & \multirow{2}{*}{$\begin{array}{l}\text { Stress } \\
\text { (III) }\end{array}$} & \multirow{2}{*}{$\begin{array}{l}\text { Stress + N- } \\
14 \\
\text { (IV) }\end{array}$} & \multirow{2}{*}{$\begin{array}{l}\text { Stress } \\
\text { (III) }\end{array}$} & \multirow{2}{*}{$\begin{array}{l}\text { Stress + N- } \\
14 \\
\text { (IV) }\end{array}$} & \multirow{2}{*}{$\begin{array}{l}\text { Stress } \\
\text { (III) }\end{array}$} & \multirow{2}{*}{$\begin{array}{l}\text { Stress + N- } \\
14 \\
\text { (IV) }\end{array}$} & \\
\hline & & (IV) & & & & & & & \\
\hline \multirow[t]{2}{*}{ Attack } & 15,8 & $0,0^{*}$ & 7,3 & 0,0 & 5,1 & 0,0 & 4,1 & 0,0 & 11,6 \\
\hline & {$[4,5 ; 33,5]$} & {$[0,0 ; 0,3]$} & {$[0,0 ; 21,3]$} & {$[0,0 ; 0,8]$} & {$[0,5 ; 45,0]$} & {$[0,0 ; 0,2]$} & {$[0,0 ; 22,2]$} & {$[0,0 ; 3,2]$} & {$[4,0 ; 40,3]$} \\
\hline \multirow[t]{2}{*}{ Fight } & 4,2 & 6,5 & 3,7 & 2,0 & 4,7 & 4,1 & $2,0^{\star * \star}$ & 5,8 & 1,8 \\
\hline & {$[2,8 ; 8,3]$} & {$[3,6 ; 16,2]$} & {$[0,8 ; 6,1]$} & {$[0,0 ; 3,2]$} & {$[2,3 ; 6,9]$} & {$[1,8 ; 6,2]$} & {$[0,9 ; 5,5]$} & {$[2,8 ; 6,4]$} & {$[1,2 ; 4,5]$} \\
\hline \multirow{2}{*}{$\begin{array}{l}\text { Social } \\
\text { interaction }\end{array}$} & 26,4 & 6,7 & 10,5 & 2,1 & 14,3 & $4,2^{*}$ & 10,9 & 5,9 & 12,5 \\
\hline & {$[8,2 ; 50,8]$} & {$[3,6 ; 16,4]$} & {$[1,7 ; 27,1]$} & {$[0,0 ; 5,3]$} & {$[7,8 ; 47,3]$} & {$[1,8 ; 6,2]$} & {$[1,8 ; 24,4]$} & {$[5,8 ; 14,8]$} & {$[6,0 ; 41,9]$} \\
\hline \multirow[t]{2}{*}{ Rearing } & 9,6 & 8,9 & $5,6^{* *}$ & 0,0 & 7,7 & $3,6^{*}$ & 6,6 & $3,6^{*}$ & $2,5^{* *}$ \\
\hline & {$[6,0 ; 13,9]$} & {$[2,8 ; 14,3]$} & {$[3,6 ; 8,0]$} & {$[0,0 ; 1,8]$} & {$[5,9 ; 13,5]$} & {$[0,0 ; 4,8]$} & {$[5,4 ; 10,6]$} & {$[0,2 ; 4,9]$} & {$[2,0 ; 9,1]$} \\
\hline \multirow{2}{*}{$\begin{array}{l}\text { Recline } \\
\text { against } \\
\text { wall }\end{array}$} & 17,1 & 11,6 & 7,6 & 3,7 & 15,3 & $2,3^{*}$ & 16,2 & 5,1 & 6,4 \\
\hline & {$[2,2 ; 22,1]$} & {$[2,7 ; 17,5]$} & {$[3,7 ; 15,9]$} & {$[0,9 ; 5,2]$} & {$[12,7 ; 21,1]$} & {$[0,0 ; 10,9]$} & {$[12,1 ; 21,9]$} & {$[1,0 ; 6,5]$} & {$[1,0 ; 16,1]$} \\
\hline \multirow{2}{*}{ Moving } & 44,5 & 8,3 & 51,4 & $19,9^{*}$ & $73,1^{\star *}$ & $7,4^{*}$ & 84,1 & $3,6^{*}$ & 42,4 \\
\hline & {$[22,9 ; 73,4]$} & {$[4,5 ; 19,6]$} & {$[37,0 ; 77,0]$} & {$[9,7 ; 25,4]$} & {$[58,2 ; 92,2]$} & {$[0,0 ; 19,7]$} & {$[55,0 ; 100,1]$} & {$[0,0 ; 6,9]$} & {$[22,7 ; 87,9]$} \\
\hline \multirow{2}{*}{$\begin{array}{l}\text { Social } \\
\text { inactivity }\end{array}$} & 71,2 & 28,4 & 60,3 & $28,5^{*}$ & 97,8 & $23,1^{*}$ & 106,5 & 10,0 * & 56,4 \\
\hline & {$[31,1 ; 109,4]$} & {$[19,8 ; 87,9]$} & {$[50,3 ; 106,7]$} & {$[12,0 ; 31,9]$} & {$[78,8 ; 138,2]$} & {$[0,0 ; 41,1]$} & {$[95,9 ; 129,7]$} & {$[6,8 ; 19,9]$} & {$[26,2 ; 106,3]$} \\
\hline \multirow[t]{2}{*}{ Grooming } & 3,4 & 0,0 & 38,0 & 4,0 & 23,6 & 0,0 & 20,9 & 0,0 * & 45,5 \\
\hline & {$[0,7 ; 9,4]$} & {$[0,0 ; 0,0]$} & {$[9,9 ; 66,6]$} & {$[0,0 ; 14,0]$} & {$[12,2 ; 45,2]$} & {$[0,0 ; 14,9]$} & {$[5,3 ; 42,6]$} & {$[0,0 ; 0,5]$} & {$[6,7 ; 101,2]$} \\
\hline \multirow{2}{*}{$\begin{array}{l}\text { Non-social } \\
\text { exploration }\end{array}$} & 80,9 & 53,8 & 87,2 & 55,9 & 133,4 & 52,9 & 148,1 & 50,6 & 128,5 \\
\hline & {$[70,0 ; 158,2]$} & {$[35,2 ; 61,9]$} & {$[70,3 ; 155,0]$} & {$[41,9 ; 164,5]$} & {$[40,3 ; 177,8]$} & {$[1,6 ; 116,7]$} & {$[94,8 ; 179,7]$} & {$[4,6 ; 104,1]$} & {$[65,3 ; 140,6]$} \\
\hline \multirow{2}{*}{$\begin{array}{l}\text { Social } \\
\text { exploration }\end{array}$} & 62,3 & $12,6 *$ & 80,6 & $36,7 * *$ & 58,1 & 4,9 & 68,8 & $0,3^{*}$ & 69,3 \\
\hline & {$[38,3 ; 128,4]$} & {$[6,8 ; 24,0]$} & {$[44,1 ; 104,8]$} & {$[34,0 ; 66,5]$} & {$[53,8 ; 90,8]$} & {$[0,0 ; 78,8]$} & {$[65,6 ; 88,1]$} & {$[0,0 ; 1,2]$} & {$[46,8 ; 96,9]$} \\
\hline \multirow[t]{2}{*}{ Move away } & 22,4 & $4,9 *$ & 13,2 & 4,4 & 21,9 & $1,4^{*}$ & 17,6 & $2,6 *$ & 10,7 \\
\hline & {$[12,7 ; 33,5]$} & {$[3,8 ; 9,9]$} & {$[6,5 ; 19,4]$} & {$[0,8 ; 10,1]$} & {$[15,8 ; 30,1]$} & {$[0,9 ; 4,3]$} & {$[11,3 ; 23,0]$} & {$[1,2 ; 10,9]$} & {$[8,3 ; 13,6]$} \\
\hline Flight & 0,0 & 0,3 & 0,0 & 0,4 & 0,0 & 0,6 & 0,0 & 0,6 & 0,0 \\
\hline & {$[0,0 ; 0,0]$} & {$[0,0 ; 6,2]$} & {$[0,0 ; 0,0]$} & {$[0,0 ; 1,8]$} & {$[0,0 ; 0,0]$} & {$[0,0 ; 8,3]$} & {$[0,0 ; 0,0]$} & {$[0,0 ; 2,9]$} & {$[0,0 ; 3,0]$} \\
\hline Submissive & 62,1 & 33,1 & 13,2 & 14,0 & 17,0 & 27,1 & 43,7 & 24,8 & 63,2 \\
\hline & {$[31,6 ; 84,0]$} & {$[26,2 ; 50,9]$} & {$[3,0 ; 55,4]$} & {$[0,0 ; 27,1]$} & {$[13,7 ; 38,5]$} & {$[6,4 ; 54,1]$} & {$[29,0 ; 91,0]$} & {$[0,3 ; 84,5]$} & {$[1,6 ; 97,5]$} \\
\hline Defensive & 14,0 & 4,3 & 9,7 & $0,6^{* *}$ & 12,2 & 6,1 & 6,8 & 5,4 & 11,4 \\
\hline posture & {$[4,2 ; 33,3]$} & {$[2,7 ; 10,5]$} & {$[1,2 ; 23,2]$} & {$[0,0 ; 2,7]$} & {$[6,9 ; 17,3]$} & {$[0,9 ; 13,3]$} & {$[2,7 ; 9,9]$} & {$[2,2 ; 17,4]$} & {$[0,7 ; 34,1]$} \\
\hline Freeze & 97,3 & 360,8 & 108,3 & 310,3 & 93,1 & 240,0 & 76,8 & $265,8^{*}$ & 40,2 \\
\hline & {$[65,1 ; 228,7]$} & {$[353,6 ; 443,3]$} & {$[70,4 ; 277,5]$} & {$[237,0 ; 353,0]$} & {$[54,2 ; 120,1]$} & {$[159,0 ; 371,7]$} & {$[17,7 ; 228,1]$} & {$[227,7 ; 446,7]$} & {$[33,8 ; 204,4]$} \\
\hline Defense & 293,4 & 460,9 & 189,6 & 317,9 & 192,5 & 267,7 & 185,3 & $409,8 *$ & 149,4 \\
\hline & {$[156,5 ; 364,7]$} & {$[402,7 ; 501,6]$} & {$[131,5 ; 283,8]$} & {$[287,8 ; 380,0]$} & {$[115,6 ; 202,9]$} & {$[238,4 ; 418,0]$} & {$[125,2 ; 293,3]$} & {$[285,8 ; 479,2]$} & {$[118,9 ; 223,4]$} \\
\hline $\begin{array}{l}\text { Latency of } \\
\text { first }\end{array}$ & 2,3 & 1,7 & $3,4^{* *}$ & 5,5 & 3,5 & 3,4 & 5,2 & 3,6 & 4,2 \\
\hline interaction & {$[2,0 ; 2,4]$} & {$[1,3 ; 11,3]$} & {$[2,8 ; 7,1]$} & {$[3,0 ; 10,6]$} & {$[3,2 ; 4,5]$} & {$[1,8 ; 7,7]$} & {$[2,1 ; 7,3]$} & {$[2,9 ; 7,2]$} & {$[2,0 ; 5,0]$} \\
\hline Latency of & 50,2 & 56,8 & 67,0 & 77,7 & 31,7 & 45,6 & 38,2 & 156,0 & 64,8 \\
\hline & {$[30,5 ; 76,7]$} & {$[11,6 ; 90,3]$} & {$[58,4 ; 76,6]$} & {$[63,3 ; 600,0]$} & {$[17,3 ; 35,2]$} & {$[25,8 ; 264,7]$} & {$[35,8 ; 61,6]$} & {$[17,8 ; 558,7]$} & {$[14,7 ; 133,8]$} \\
\hline Sitting & 22,9 & 11,8 & 37,1 & 65,5 & 5,7 & 6,0 & 0,0 & 0,1 & 17,7 \\
\hline & {$[6,1 ; 33,4]$} & {$[5,3 ; 49,8]$} & {$[23,6 ; 44,2]$} & {$[3,4 ; 163,2]$} & {$[1,3 ; 34,0]$} & {$[0,0 ; 318,2]$} & {$[0,0 ; 17,1]$} & {$[0,0 ; 101,0]$} & {$[0,2 ; 22,6]$} \\
\hline
\end{tabular}

Table 1

Table-1: Effect of N-14 and Social Stress on the behavior of Intruder animals in the Resident-Intruder Paradigm 
Notes:

1) Table shows median (Me) and interquartile range ([25\%; 75\%]).

2) The asterisk $\left(^{*}\right)$ indicates statistical significance $(p<0.05)$ for the Mann-Whitney test relative to Group III.

3) The double asterisk (**) indicates statistical significance $(p<0.05)$ for the Wilcoxon test relative to Day 0.

$\mathrm{N}-14$ cotreatment induced alterations in 'duration of immobilization' (DIM-Forced swimming test)

In the FST [10], there was an insignificant decrease in the duration of immobilization (DIM FST) of Group III stressed animals compared to the Group I control. $\mathrm{N}-14$ did not affect DIM FST in both stressed (statistically significant) and intact animals.

N-14 cotreatment induced alterations in 'Exploratory Activity, Sitting, Hole, Rearing, Sitting, and Moving' (Open field test)

$\mathrm{N}-14$ cotreatment invoked a significant decrease in Exploratory Activity (26\%), Moving (67\%), and Sitting (40\%) in stressed animals on Day +5 when compared to the Group III. In Group II, N-14 caused a slight increase in Exploratory activity (129\%), Hole (133\%), and Moving (200\%). There were insignificantly reduced patterns of Rearing (40\%) and Sitting (50\%) compared to the intact control (Group I).

\section{$\mathrm{N}-14$ cotreatment induced alterations in 'open arms time, center time, open arms entries, and closed arms returns' (Elevated plus-maze test)}

There was a slight increase in the Open Arms time in Group III by $47 \%$ compared to the intact control Group I. There was reduction in Open and Closed Arms entries by $33 \%$ and $25 \%$, respectively; concomitantly, reduction in Closed Arms Returns (by 33\%) and Head Dipping over the sides of the maze (by $150 \%$ ) was observed when compared to the control Group I. There parameters were significantly altered by the cotreatment of $\mathrm{N}-14$ to $\mathrm{CMSS}$ animals. $\mathrm{N}-14$ cotreatment invoked reduction in the Open Arms time in the Group IV-stressed animals, near normal to Group I intact animals. The number of Closed Arms Returns and Closed Arms entries significantly increased with N-14 when compared to Group I Intact (by $167 \%$ and $25 \%$ ) and Group III Stressed (by $100 \%$ and $67 \%$ ). In intact animals, $\mathrm{N}-14$ induced significant reduction in the center time and closed arms entries with simultaneous increase in the open arms time, open arms entries, and closed arms returns.

\section{Effect of $\mathrm{N}-14$ cotreatment on Weight gain and food consumption}

CMSS significantly induced weight gain of the Intruders $\left(\Delta_{0-+6}=28.5 \mathrm{~g}, p=0.009\right)$ but did not affect the amount of food consumed by Intruders. Moreover, $\mathrm{N}$ 14 did not affect the weight of intact animals or their food consumption; these parameters were reduced by $29 \mathrm{~g}(p=0.004)$ and $4.5 \mathrm{~g}$ respectively in the Group IV stressed animals. Group IV individual food consumption was lower than the Group III significantly on Days +4 and +5 .

\section{Effect of $\mathrm{N}-14$ cotreatment on the mass of internal organs viz., thymus, and liver}

Interaction between Residents and Intruders caused profound increase in the mass of thymus (135\%) in Group III stressed animals. A similar trend was observed in the group of animals treated with N-14 (Group II). The administration of N-14 to animals that underwent CMSS (Group IV) induced profound decline in the mass of thymus by $55 \%$ compared to Group III, $(p=0.065)$; similarly, the liver mass was also significantly decreased by $13 \%$ in Group IV ( $p=$ 0.026) compared to Group III.

\section{Discussion}

Currently, there are no significant molecular therapies against the depression induced in several neurological diseases, neurodegenerative diseases like AD, and trauma conditions. Short-term "modern-life stress", "chronic isolation stress", "chronic mild/variable stress", "chronic mild social stress" are reported to be increase the pathophysiology of $A D$ and comorbid depressive symptoms with cognitive impairment [41-46]. The present preliminary study examined the antidepressive efficacy of 3-substituted thietane-1,1-dioxide using RIP-stress induced models. It was concluded that the adolescent Sprgue-Dawley male rats exposed to chronic mild stress exhibit a depressive phenotype eventually exemplified by the hippocampal fear-conditioning, and synaptic plasticity [32, 47, 48]. In order to examine whether the RIP-induced behavioral alterations are accompanied by depression during mild social stress, we have used SpragueDawley rat models of daily exposure to mild social stress from day +0 to day +5 [33]. Sheng Wei et al (2014) delineated that the RIP induced aggressive behavior in the intruders [33]. Reverse-Resident-Intruder-Paradigm (rRIP) is reported to be an efficient model to examine the effects of stress on adolescent neurobehavioral phenomenon [32]. The major findings of our study is that the CMSS has induced 'depressive-like behavior' in male adult intruder rats, which was relieved by the cotreatment of $\mathrm{N}-14$ in the group of animals which underwent chronic mild stress. There was an initial dynamic interaction between residents and intruders during the experiment, which was exemplified by the increase in the exploratory activity through nonsocial exploration.

The social defeat model from chronic social stress summarized the association between behavioral and physiological effects relevant to depression in many neuropsychiatric and neurodegenerative diseases. Fiona Hollis et al (2014) have reviewed the suitability of the social defeat to the understanding of psycho-neurobiology of depression and the potential avenues to develop novel therapies against behavioral alterations during depression in neurodegenerative diseases [49]. Normally, the intruders in the RIP exhibit defensive and aggressive behavior in response to offensive attacks by residents [50]. Hence, this paradigm is significant model to ascertain the behavioral aspects like defense in relation to social stress using intruder as the major experimental animal. We have not introduced social stress in the same room where the non-stressed controls were housed because control animals may experience major stress when they witnessing social stress [51, 52]. However, the intruder may face dire consequences during defense against residents and experience severe depression, anorexia, loss of body weight due to social defeat from chronic social stress [30]. Our study vividly reported a significant decrease in body weight and increase in the weight of thymus of intruders due to the recurrent depressive symptoms due to social defeat from residents. $\mathrm{N}-14$ cotreatment did not affect either weight or amount of food consumption in the intruders but mitigated the mass of thymus. 
The forced-swimming test is predominantly suitable to determine the anti-depressant activity of novel lead molecules [53-57]. The reduced immobility time in this test was indicated for anti-depressive efficacy that countered the behavioral expression of depressive-symptoms in rats [58]. Previous reports from Koolhaas J et al (1990), Bielajew C et al (2003) delineated the behavioral alterations from social defeat from chronic mild social stress [58, 59]. In our study, CMSS mitigated the social interaction of intruders both in the dynamics compared to Day 0 and in comparison with Group III. This data indicate a decrease in aggressiveness of animals due to the development of an Avoiding Conflict strategy and increasing social adaptability. In Group IV, N-14 cotreatment significantly mitigated the level of aggressiveness than in stressed animals of Group III alone. N-14 cotreatment induced the extensive social interaction of Group IV animals throughout the experiment compared with Group III stressed animals, although there was a decrease in this type of behavior in Group III on Days $+3 \&+5$ whereas on Days +4 and +5 in group IV.

In the forced swimming test, CMSS invoked reduction in the DIM (duration of immobilization) FST. N-14 did not affect DIM in FST of stressed animals significantly, which may be due to test deficiencies: it has been shown that interventions affecting the locomotor activity of animals led to a change in DIM and, accordingly, to false positive or negative findings [60]. Therefore, in order to evaluate the antidepressant effect of the compounds with a sedative component, it is advisable to use a depression index i.e. the ratio of the number of short [less than $6 \mathrm{~s}$ ] immobilization periods to the number of active swimming periods [29].

Social Inactivity was decreased in group IV rats due to extensive decline in the exploratory activity $\mathrm{N}$ - 14 cotreatment. This finding may be due to the psycho-sedative effect of $\mathrm{N}-14$. The Non-Social Exploration pattern also reflects the level of exploratory activity, which was changed unidirectional with Social Inactivity. N-14 significantly alleviated its total duration than stressed animals. This kind of behavioral patterns with $\mathrm{N}-14$ cotreatment vividly delineated its ability to mitigate the development of behavioral despair similar to other anti-depressants [56, 61, 62]. In our study, the cotreatment of N14 with animals underwent social stress have resulted in the higher motivation and impaired behavioral despair.

Initial activity of the rats located in any new environment (for ex. an open field) can be considered as an indicator of its emotion and motivation state [63-65]. Inescapable open filed often trigger stress and reward behavior of novelty consequently induces impaired locomotor and exploratory activity in new environment $[66,67]$. However, the reduced exploration of a novel environment may be related to higher anxiety levels in stressed animals. We have not examined whether the observed changes in locomotor activity were due to altered anxiety level [33]. Social Inactivity and Non-Social Exploration are indicators of the social passivity of animals along with the Grooming pattern; The grooming pattern was also decreased under the cotreatment of $\mathrm{N}-14$ in stressed animals. $\mathrm{N}-14$ significantly reduced the sociability of animals, which was evident by its activity at the patterns of social exploration and latency of first interaction. This may indicate an increase in the sociability of animals although there was substantial rise of latency of first interaction.

A report by Sheng Wei et al (2017) described the ability of residents to defend intruders due to their emotional aggressiveness; the administration of fluoxetine to the intruder groups mitigated the aggressive behavior and resident-intruder stress [68]. It was well established that the RIP confer aggressive behavior in male rats; which can be considered as the model of depression to evaluate the aggressive behavior upon anti-depressant therapy [33, 69]. In our study, N-14 significantly increased Defense behaviors throughout the experiment in the both dynamics when compared to Group III. N14 cotreatment enhanced adaptive survival strategy which was evident from the Passive forms of Defense behavior prevailed in Intruders' behavior, where the predominant pattern observed was Freeze behavior (87-94\%). In addition, N14 invoked reduction in Move Away and Defensive Upright Posture compared to the Stress Group, which is correlated to the decline in aggressiveness by $\mathrm{N}-14$. There was an increase in the active forms of Defense behaviors: Flight \& Latency of Submission when compared to Group III. This is apparently a significant evidence for the antidepressant activity of the compound N-14 with psycho-sedative properties. However, the dynamics (Days 0 to +5 ) showed a tendency for the Defense behaviors to increase: Day $+1(48.6 \%)$ and Day $+5(120.7 \%)$. This is due to the reduction in the duration of Freeze on all days of the experiment and Submissive Posture on Days $0,+2,+3$ compared to Group III. Previously it was reported hat fluoxetine has reduced the defensive behavior of animals eventually inhibiting 'passive form' and stimulating 'active form' of defensive behavior [68, 70].

Lipid extract Channa Striatus have proven ameliorative effect against depression induced from Chronic Unpredictable Mild Stress Model in rats [71]. Similarly, another report depicted the efficacy of curcumin to alleviate the depression-induced memory defects by modulating oxidative stress \& cholinergic activity using chronic unpredictable mild stress-induced depression models [72]. In our study, both N-14 stimulate active forms of defensive behavior exhibiting antidepressant properties. $\mathrm{N}-14$ cotreatment reduced the aggressiveness of animals. $\mathrm{N}-14$ also enhanced defensive behavior due to the passive form and simultaneously reduced the sociability and exploratory activity of animals, which is the opposite effect to fluoxetine [https://cyberleninka.ru/article/n/izuchenie-antidepressivnoy-aktivnosti-i-profilya-bezopasnosti-novyh-proizvodnyh-tietan-1-1-dioksida]

In the OF test, it was shown that N-14 cotreatment significantly reduced Exploratory Activity and patterns Moving and Sitting in animals subjected to CMSS compared to Group III. The obtained results have confirmed the reduction in Social Inactivity and Non-Social Exploration, which was evident from the decrease in exploratory and motor activity of animals treated with $\mathrm{N}-14$ as revealed from the analysis of the RIP.

In groups exposed to CMSS (Groups III and IV), the level of Exploratory Activity was higher than in the group of intact animals (Group I). The level of Emotional Anxiety was slightly lower. N14 cotreatment invoked sedative properties evident from the decrease in behavioral patterns of Exploratory Activity, Movement on the Spot, and Moving compared to the stressed rats. Therefore, our results are laying pavement for the future studies to address the molecular and neurobiological signaling underlying the anti-depressive behavioral patterns with N14 in rat models and in vivo AD models.

A report by Sergio D. Iñiguez et al (2014) delineated that the social defeat stress in adolescent male c57BL/6 mice confer depression like phenotype [73]. The administration of SSR149415 (a first selective and orally active non-peptide antagonist of vasopressin V1b receptors) mitigated the physical state of the coat of socially stressed animals during RIP and induced anti-depressant effect [74]. In addition, the findings concluded that SSR149415 administration normalized grooming during CMSS [74]. In our study, EPM tests described an extensive rise in the Open Arms time, and reduction in the number of Open and Closed Arms

Page $9 / 16$ 
entries, as well as an increase in the number of Closed Arms Returns and Head Dippings over the sides of the maze in the Stress group was observed compared to controls (Group I). These are may be due to manifestation of Risk Assessment behavior rather than an indicator of anxiety in animals [36]. N-14 cotreatment significantly invoked decline in the Open Arms Time near normal to intact control animals; however, the number of Closed Arms Returns and Closed Arms entries substantially increased with N-14 in Group IV compared to both intact and stressed groups. This may indicate a normalization of the behavioral structure of animals subjected to CMSS. Thus, our reports for the antidepressant activity of N14 are in line with above studies.

The reduction in the thymus mass, body weight was evident in rodent models during CMSS-induced depression behavior [75, 76]. CMSS fostered reduction in the weight gain of the Intruders. N-14 cotreatment significantly reduced the weight of Group IV animals and their feed consumption. Interaction between Residents and Intruders led to the increase in mass of thymus of stressed animals (Group III). N-14 reduced the mass of thymus and liver of Intruders in Group IV.

\section{Conclusions}

The intake of current anti-depressants has been associated with severe adverse effects in depression patients and AD patients' comorbid with depression. The current study concluded that the dynamic interaction between Residents and Intruders over the course of the experiment showed substantial "increase in exploratory activity (non-social exploration)", "decrease in aggressiveness and defensive behavior", as well as a "decrease in body weight gain" and an "increase in thymus mass" in stressed animals. N-14 cotreatment did not affect the weight gain of the intruders, food consumption. N-14 has proven efficacy to reduce thymus mass in rats subjected to CMSS. N-14 cotreatment has "reduced sociability, exploratory activity and aggressiveness" and "increased social adaptability and defensive behavior of animals" due to the passive forms of defense with concomitant "decrease in exploratory and motor activity. Increased active forms of defense and submission latency indicate that $\mathrm{N}-14$ has antidepressant efficacy with a psycho-sedative component of action; this psychopharmacology study can be further extrapolated for in vivo \& clinical studies to delineate the molecular signaling for $\mathrm{N}-14$ efficacy.

\section{Limitations}

Our study is a preliminary study, previously, the current paradigm has proved as a well established challenging models to study the effects of stress-induced depression despair for the models of social defeat, which characteristically rely on male aggression not readily displayed by female subjects [77-79]. Reports by Holly et al. 2012; Jacobson-Pick et al. 2013 declared that the social defeat from CMSS models elicit aggressive behavioral displays by resident females; this is making observers very difficult to record the symptoms because the social defeat in female rats appears to invoke several symptoms but only after a delay $[49,79]$. Another significant limitation of this study is that we have not determined the influence of anxiety level on the results. Instead we have significantly focused on the predominant differences in the exploratory behaviors between the groups. Our choice of paradigm more broadly focused on to detect the behavioral alterations invoked from the novel anti-depressant molecule as a preliminary step for further future understating of the depression in ADinduced in vivo models, and clinical situation that mimics AD-like pathology and behavioral sign .

\section{Future Studies}

We will extend our future studies in the forthcoming research project for the understating of the AD-associated depression and underlying pathophysiology, and molecular signaling vividly in vivo and clinical models and extrapolate these studies to examine the efficacy of $\mathrm{N}-14$ to mitigate depression-induced behavioral alterations.

\section{Abbreviations}

DIM : duration of immobilization

EPM : elevated plus-maze

FST : forced swimming test

OF : open field

CMSS : Chronic mild social stress

\section{Declarations}

\section{Availability of data and materials}

All data obtained in this study are available from the corresponding author on request.

\section{Ethics approval and consent to participate}

The animal experimental procedures were approved by the Ethical Committee for animal care of the Bashkir State Medical University, Ufa, Russian Federation in accordance with the Guidelines on conducting studies involving the use of experimental animals \& National Institute of Health Guide for the Care and Use of Laboratory Animals" (NIH Publications No. 80 - 23, revised 1996). The experimental subjects were white outbred rats, males and females. They were kept in 
standard vivarium conditions with a 12/12 h light/dark cycle (lights off at 20:00). They had free access to water and food. Cervical dislocation was used to euthanize the animals.

\section{Consent for publication}

Not applicable.

\section{Competing interests}

The authors declare no competing financial and non-financial interests.

Table-1

Effect of N-14 and Social Stress on the behavior of Intruder animals in the Resident-Intruder Paradigm

\section{Funding}

This study was financially supported by Participant of the Youth Scientific Innovation Contest (UMNIK) program grant (The Foundation for Assistance to Small Innovative Enterprises, Russian Federation). This research was also supported by Russian Academic Excellence project "5-100" for the Sechenov University, Moscow, Russia, and GALLY International Research Institute.

\section{Authors' contributions}

Irina L. Nikitina (ILN), Kirill V. Bulygin (KVB), and Gjumrakch Aliev (GA) conceptualized and designed the study. ILN, Gulnara G. Gaisina (GGG), KVB, Elmira F. Galimova (EFG), Shamil N. Galimov (SNG), collected and analyzed the data. ILN, GGG, Narasimha M Beeraka (NMB), KVB, EFG, SNG, Vladimir N. Nikolenko (VNN), Liudmila M. Mikhaleva (LMM), Siva G. Somasundaram (SGS), Cecil E. Kirkland CEK), Marco F. Avila-Rodriguez (MAR), NMB, and GA performed the formal analysis, and the results and their interpretation, wrote the original manuscript, revised and improved the original draft. All authors have reviewed and approved the manuscript before submission.

\section{Acknowledgements}

The authors would like to thanks the authorities of Bashkir State Medical University for providing laboratory space and consumables

\section{References}

1. Lyketsos CG, Steele C, Baker L, Galik E, Kopunek S, Steinberg M, Warren A: Major and minor depression in Alzheimer's disease: prevalence and impact Journal of Neuropsychiatry and Clinical Neurosciences 1997, 9(4):556-561.

2. González-Salvador T, Lyketsos CG, Baker A, Hovanec L, Roques C, Brandt J, Steele C: Quality of life in dementia patients in long-term care. International journal of geriatric psychiatry 2000, 15(2):181-189.

3. Steele C, Rovner B, Chase GA, Folstein M: Psychiatric symptoms and nursing home placement of patients with Alzheimer's disease. The American journal of psychiatry 1990.

4. Peters ME, Schwartz S, Han D, Rabins PV, Steinberg M, Tschanz JT, Lyketsos CG: Neuropsychiatric symptoms as predictors of progression to severe Alzheimer's dementia and death: the Cache County Dementia Progression Study. American Journal of Psychiatry 2015, 172(5):460-465.

5. Burke AD, Goldfarb D, Bollam P, Khokher S: Diagnosing and Treating Depression in Patients with Alzheimer's Disease. Neurology and therapy 2019:1-26.

6. Husebo BS, Ballard C, Sandvik R, Nilsen OB, Aarsland D: Efficacy of treating pain to reduce behavioural disturbances in residents of nursing homes with dementia: cluster randomised clinical trial. Bmj 2011, 343.

7. Chase GA: Association between family history of affective disorder and the depressive syndrome of Alzheimer's disease. Am J Psychiatry 1990 , 147(4):452-456.

8. Assal F, Cummings JL: Neuropsychiatric symptoms in the dementias. Current opinion in neurology 2002, 15(4):445-450

9. Shim YS, Yang D-W: Depression as prognostic factor: 6 months follow-up in a geriatric institution. Archives of gerontology and geriatrics 2006, 43(2):277283

10. Richard E, Reitz C, Honig LH, Schupf N, Tang MX, Manly JJ, Mayeux R, Devanand D, Luchsinger JA: Late-life depression, mild cognitive impairment, and dementia. JAMA neurology 2013, 70(3):383-389.

11. Leong C: Antidepressants for depression in patients with dementia: a review of the literature. The Consultant Pharmacist ${ }^{\circledR} 2014,29(4): 254-263$.

12. Cassano T, Calcagnini S, Carbone A, Bukke VN, Orkisz S, Villani R, Romano A, Gaetani S: Pharmacological treatment of depression in Alzheimer's disease: a challenging task. Frontiers in pharmacology 2019, 10:1067.

13. Milwain EJ, Nagy Z: Depressive symptoms increase the likelihood of cognitive impairment in elderly people with subclinical Alzheimer pathology. Dementia and geriatric cognitive disorders 2005, 19(1):46-50. 
14. Holmes C, Arranz M, Collier D, Powell J, Lovestone S: Depression in Alzheimer's disease: the effect of serotonin receptor gene variation. American Journal of Medical Genetics Part B: Neuropsychiatric Genetics 2003, 119(1):40-43.

15. Hickie I, Scott E, Naismith S, Ward P, Turner K, Parker G, Mitchell P, Wilhelm K: Late-onset depression: genetic, vascular and clinical contributions. Psychological Medicine 2001, 31(8):1403-1412.

16. Rapp MA, Schnaider-Beeri M, Purohit DP, Perl DP, Haroutunian V, Sano M: Increased neurofibrillary tangles in patients with Alzheimer disease with comorbid depression. The American Journal of Geriatric Psychiatry 2008, 16(2):168-174.

17. Panza F, Frisardi V, Capurso C, D'Introno A, Colacicco AM, Imbimbo BP, Santamato A, Vendemiale G, Seripa D, Pilotto A: Late-life depression, mild cognitive impairment, and dementia: possible continuum? The American Journal of Geriatric Psychiatry 2010, 18(2):98-116.

18. Steffens DC, McQuoid DR, Potter GG: Amnestic mild cognitive impairment and incident dementia and Alzheimer's disease in geriatric depression International psychogeriatrics 2014, 26(12):2029-2036.

19. Krishnan KRR, Tupler LA, Ritchie JC, McDonald WM, Knight DL, Nemeroff CB, Carroll BJ: Apolipoprotein E- $\varepsilon 4$ frequency in geriatric depression. Biological psychiatry 1996, 40(1):69-71.

20. Rapp MA, Schnaider-Beeri M, Grossman HT, Sano M, Perl DP, Purohit DP, Gorman JM, Haroutunian V: Increased hippocampal plaques and tangles in patients with Alzheimer disease with a lifetime history of major depression. Archives of general psychiatry 2006, 63(2):161-167.

21. Qiu WQ, Zhu H, Dean M, Liu Z, Vu L, Fan G, Li H, Mwamburi M, Steffens DC, Au R: Amyloid-associated depression and ApoE4 allele: Iongitudinal follow-up for the development of Alzheimer's disease. International journal of geriatric psychiatry 2016, 31(3):316-322.

22. Kupferberg A, Bicks L, Hasler G: Social functioning in major depressive disorder. Neuroscience \& Biobehavioral Reviews 2016, 69:313-332.

23. Avorn J: Depression in the elderly-falls and pitfalls. In.: Mass Medical Soc; 1998.

24. Roth M, Mountjoy C, Amrein R, Group ICS: Moclobemide in elderly patients with cognitive decline and depression: an international double-blind, placebocontrolled trial. The British Journal of Psychiatry 1996, 168(2):149-157.

25. Tollefson GD, Bosomworth JC, Heiligenstein JH, Potvin JH, Holman S, Group FCS: A double-blind, placebo-controlled clinical trial of fluoxetine in geriatric patients with major depression. International psychogeriatrics 1995, 7(1):89-104.

26. Cryan JF, Slattery DA: Animal models of mood disorders: recent developments. Current opinion in psychiatry 2007, $20(1): 1-7$.

27. Nestler EJ, Hyman SE: Animal models of neuropsychiatric disorders. Nature neuroscience 2010, 13(10):1161.

28. Иванова О, Никитина И, Габидуллин Р, Алехин Е, Клен Е, Макарова Н, Халиуллин Ф: Изучение антидепрессивной активности и профиля безопасности новых производных тиетан-1, 1-диоксида. Сибирский медицинский журнал (Томск) 2011, 26(1-1).

29. Klen E, Nikitina I, Makarova N, Miftakhova A, Ivanova O, Khaliullin F, Alekhin E: 3-Substituted Thietane-1, 1-Dioxides: Synthesis, Antidepressant Activity, and in Silico Prediction of Their Pharmacokinetic and Toxicological Properties. Pharmaceutical Chemistry Journa/ 2017, 50(10):642-648.

30. Koolhaas JM, Coppens CM, de Boer SF, Buwalda B, Meerlo P, Timmermans PJ: The resident-intruder paradigm: a standardized test for aggression, violence and social stress. JoVE (Journal of Visualized Experiments) 2013(77):e4367.

31. Europe Co: European convention for the protection of vertebrate animals used for experimental and other scientific purposes:[Strasbourg, 18. III. 1986]: Council of Europe; 1987

32. Manz KM, Levine WA, Seckler JC, Iskander AN, Reich CG: A novel adolescent chronic social defeat model: reverse-Resident-Intruder Paradigm (rRIP) in male rats. Stress 2018, 21(2):169-178.

33. Wei S, Ji X-w, Wu C-I, Li Z-f, Sun P, Wang J-q, Zhao Q-t, Gao J, Guo Y-h, Sun S-g: Resident intruder paradigm-induced aggression relieves depressive-like behaviors in male rats subjected to chronic mild stress. Medical science monitor: international medical journal of experimental and clinical research 2014, 20:945.

34. Gabidullin R, Ivanova O, Nikitina I: State Registration Certificate for Computer Program No. 2008610170. In.: Moscow; 2008.

35. Porsolt R: Animal model of depression. Biomedicine/[publiee pour l'AAICIG] 1979, 30(3):139-140.

36. Sestakova N, Puzserova A, Kluknavsky M, Bernatova I: Determination of motor activity and anxiety-related behaviour in rodents: methodological aspects and role of nitric oxide. Interdisciplinary toxicology 2013, 6(3):126-135.

37. Yan H-C, Cao X, Das M, Zhu X-H, Gao T-M: Behavioral animal models of depression. Neuroscience bulletin 2010, 26(4):327-337.

38. De Jong TR, Beiderbeck DI, Neumann ID: Measuring virgin female aggression in the female intruder test (FIT): effects of oxytocin, estrous cycle, and anxiety. PloS one 2014, 9(3).

39. Glants S: Biomedical statistics. Moscow: Praktika 1998.

40. Wommack JC, Taravosh-Lahn K, David JT, Delville Y: Repeated exposure to social stress alters the development of agonistic behavior in male golden hamsters. Hormones and Behavior 2003, 43(1):229-236.

41. Kang J-E, Cirrito JR, Dong H, Csernansky JG, Holtzman DM: Acute stress increases interstitial fluid amyloid- $\beta$ via corticotropin-releasing factor and neuronal activity. Proceedings of the National Academy of Sciences 2007, 104(25):10673-10678.

42. Baglietto-Vargas D, Chen Y, Suh D, Ager RR, Rodriguez-Ortiz CJ, Medeiros R, Myczek K, Green KN, Baram TZ, LaFerla FM: Short-term modern life-like stress exacerbates AB-pathology and synapse loss in 3xTg-AD mice. Journal of neurochemistry 2015, 134(5):915-926.

43. Dong H, Goico B, Martin M, Csernansky C, Bertchume A, Csernansky J: Modulation of hippocampal cell proliferation, memory, and amyloid plaque deposition in APPsw (Tg2576) mutant mice by isolation stress. Neuroscience 2004, 127(3):601-609.

44. Cuadrado-Tejedor M, Ricobaraza A, Frechilla D, Franco R, Pérez-Mediavilla A, Garcia-Osta A: Chronic mild stress accelerates the onset and progression of the Alzheimer's disease phenotype in Tg2576 mice. Journal of Alzheimer's Disease 2012, 28(3):567-578.

Page $12 / 16$ 
45. Rothman SM, Herdener N, Camandola S, Texel SJ, Mughal MR, Cong W-N, Martin B, Mattson MP: $3 x T g A D$ mice exhibit altered behavior and elevated A $\beta$ after chronic mild social stress. Neurobiology of aging 2012, 33(4):830. e831-830. e812.

46. Justice NJ: The relationship between stress and Alzheimer's disease. Neurobiology of stress 2018, 8:127-133.

47. Reich CG, Iskander AN, Weiss MS: Cannabinoid modulation of chronic mild stress-induced selective enhancement of trace fear conditioning in adolescent rats. Journal of Psychopharmacology 2013, 27(10):947-955.

48. Reich CG, Mihalik GR, Iskander AN, Seckler JC, Weiss MS: Adolescent chronic mild stress alters hippocampal CB1 receptor-mediated excitatory neurotransmission and plasticity. Neuroscience 2013, 253:444-454.

49. Hollis F, Kabbaj M: Social defeat as an animal model for depression. ILAR journal 2014, 55(2):221-232.

50. Blanchard RJ, Wall PM, Blanchard DC: Problems in the study of rodent aggression. Hormones and Behavior 2003, 44(3):161-170.

51. De Boer S, Caramaschi D, Natarajan D, Koolhaas J: The vicious cycle towards violence: focus on the negative feedback mechanisms of brain serotonin neurotransmission. Frontiers in behavioral neuroscience 2009, 3:52.

52. Popova NK, Kulikov AV: Genetic analysis of "spontaneous" intermale aggression in mice. Aggressive behavior 1986, 12(6):425-431.

53. Detke MJ, Johnson J, Lucki I: Acute and chronic antidepressant drug treatment in the rat forced swimming test model of depression. Experimental and clinical psychopharmacology 1997, 5(2):107.

54. Lucki I: The forced swimming test as a model for core and component behavioral effects of antidepressant drugs. Behavioural pharmacology 1997.

55. López-Rubalcava C, Lucki I: Strain differences in the behavioral effects of antidepressant drugs in the rat forced swimming test. Neuropsychopharmacology 2000, 22(2):191-199.

56. Butterweck V, Jürgenliemk G, Nahrstedt A, Winterhoff H: Flavonoids from Hypericum perforatum show antidepressant activity in the forced swimming test. Planta medica 2000, 66(01):3-6.

57. Cryan JF, Valentino RJ, Lucki I: Assessing substrates underlying the behavioral effects of antidepressants using the modified rat forced swimming test. Neuroscience \& Biobehavioral Reviews 2005, 29(4-5):547-569.

58. Bielajew C, Konkle A, Kentner A, Baker S, Stewart A, Hutchins A, Santa-Maria Barbagallo L, Fouriezos G: Strain and gender specific effects in the forced swim test: effects of previous stress exposure. Stress 2003, 6(4):269-280.

59. Koolhaas J, Hermann P, Kemperman C, Bohus Bv, Vandenhoofdakker R, Beersma D: SINGLE SOCIAL DEFEAT IN MALE-RATS INDUCES A GRADUAL BUT LONG LASTING BEHAVIORAL-CHANGE-A MODEL OF DEPRESSION. Neuroscience Research Communications 1990, 7(1):35-41.

60. Slattery DA, Cryan JF: The ups and downs of modelling mood disorders in rodents. ILAR journa/ 2014, 55(2):297-309.

61. Kim S-H, Han J, Seog D-H, Chung J-Y, Kim N, Park YH, Lee SK: Antidepressant effect of Chaihu-Shugan-San extract and its constituents in rat models of depression. Life sciences 2005, 76(11):1297-1306.

62. Kang M, Shin D, Oh J-W, Cho C, Lee H-J, Yoon D-W, Lee S-M, Yun J-H, Choi H, Park S: The anti-depressant effect of Nelumbinis semen on rats under chronic mild stress induced depression-like symptoms. The American journal of Chinese medicine 2005, 33(02):205-213.

63. Katz RJ, Roth KA, Carroll BJ: Acute and chronic stress effects on open field activity in the rat: implications for a model of depression. 1981.

64. Weijers H-G, Weyers P: Locomotor activity and defecation of rats observed alone and in pairs in repeated open-field sessions. Perceptual and motor skills 1998, 86(3_suppl):1179-1184.

65. Homberg JR, Olivier JD, Blom T, Arentsen T, van Brunschot C, Schipper P, Korte-Bouws G, van Luijtelaar G, Reneman L: Fluoxetine exerts age-dependent effects on behavior and amygdala neuroplasticity in the rat. PloS one 2011, 6(1).

66. Roth KA, Katz RJ: Stress, behavioral arousal, and open field activity-a reexamination of emotionality in the rat. 1979.

67. Thiel C, Müller C, Huston J, Schwarting R: High versus low reactivity to a novel environment: behavioural, pharmacological and neurochemical assessments. Neuroscience 1999, 93(1):243-251.

68. Wei S, Xiao X, Wang J, Sun S, Li Z, Xu K, Li F, Gao J, Zhu D, Qiao M: Impact of anger emotional stress before pregnancy on adult male offspring. Oncotarget 2017, 8(58):98837.

69. Fedotova I, Sultanov V, Kuznetsova N, Roshchin V, Nikitina T: Effect of new polyprenol drug ropren on anxiety-depressive-like behavior in rats with experimental Alzheimer disease. Eksperimental'naia i klinicheskaia farmakologiia 2010, 73(9):2-5.

70. Perreault HA, Semsar K, Godwin J: Fluoxetine treatment decreases territorial aggression in a coral reef fish. Physiology \& behavior 2003, 79(4-5):719-724.

71. Shukkoor A, Saleem M, Baharuldin MTHB, Jais M, Manan A, Moklas M, Aris M, Fakurazi S: Antidepressant-like effect of lipid extract of channa striatus in chronic unpredictable mild stress model of depression in rats. Evidence-Based Complementary and Alternative Medicine $2016,2016$.

72. Naqvi F, Saleem S, Batool Z, Sadir S, Tabassum S, Ahmed S, Liaquat L, Haider S: Curcumin lessens unpredictable chronic mild stress-induced depression and memory deficits by modulating oxidative stress and cholinergic activity. Pakistan journal of pharmaceutical sciences 2019, 32(4 (Supplementary)):1893-1900.

73. Iñiguez SD, Riggs LM, Nieto SJ, Dayrit G, Zamora NN, Shawhan KL, Cruz B, Warren BL: Social defeat stress induces a depression-like phenotype in adolescent male c57BL/6 mice. Stress 2014, 17(3):247-255.

74. Griebel G, Simiand J, Serradeil-Le Gal C, Wagnon J, Pascal M, Scatton B, Maffrand J-P, Soubrié P: Anxiolytic-and antidepressant-like effects of the nonpeptide vasopressin V1b receptor antagonist, SSR149415, suggest an innovative approach for the treatment of stress-related disorders. Proceedings of the National Academy of Sciences 2002, 99(9):6370-6375.

75. Ergang P, Mikulecká A, Vodicka M, Vagnerová K, Mikšík I, Pacha J: Social defeat stimulates local glucocorticoid regeneration in lymphoid organs Endocrine connections 2018, 7(12):1389-1396

Page $13 / 16$ 
76. Verbitsky A, Dopfel D, Zhang N: Rodent models of post-traumatic stress disorder: behavioral assessment. Translational psychiatry 2020, 10 (1):1-28.

77. Haller J, Fuchs E, Halász J, Makara GB: Defeat is a major stressor in males while social instability is stressful mainly in females: towards the development of a social stress model in female rats. Brain research bulletin 1999, 50(1):33-39.

78. Holly EN, Shimamoto A, DeBold JF, Miczek KA: Sex differences in behavioral and neural cross-sensitization and escalated cocaine taking as a result of episodic social defeat stress in rats. Psychopharmacology 2012, 224(1):179-188.

79. Jacobson-Pick S, Audet M-C, McQuaid RJ, Kalvapalle R, Anisman H: Social agonistic distress in male and female mice: changes of behavior and brain monoamine functioning in relation to acute and chronic challenges. PloS one $2013,8(4)$.

\section{Figures}

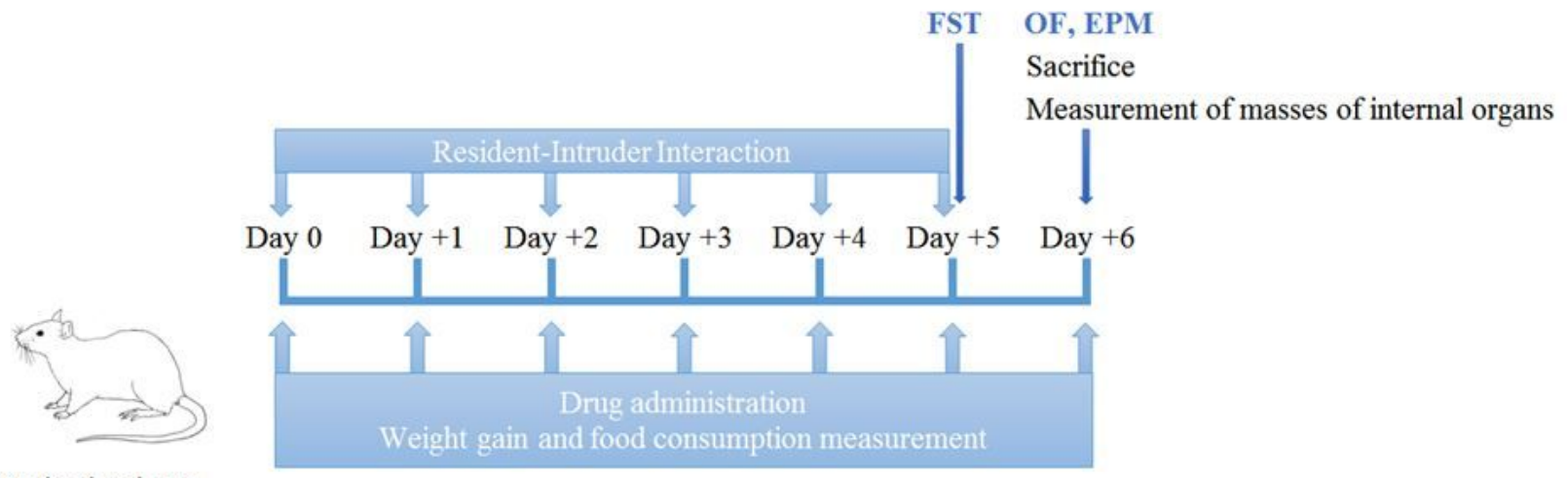

Outbred male rats

(Intruders)

Fig. 1 Scheme of the experimental protocol. Outbred male rats (Intruders, Group IV) received N-14 $(2 \mathrm{mg} / \mathrm{kg}$ ) intraperitoneally on Days 0 to +6 . Interaction between Residents and Intruders occurred for 10 minutes daily on Days 0 to +6 . On Day +5 Intruders were tested in FST, on Day +6 they were tested in OF and EPM. The weight gain and the amount of food consumed by Intruders were measured during the experiment. At the end of the experiment, the animals were euthanized and the masses of the liver, spleen, thymus, and adrenal glands were measured.

Figure 1 


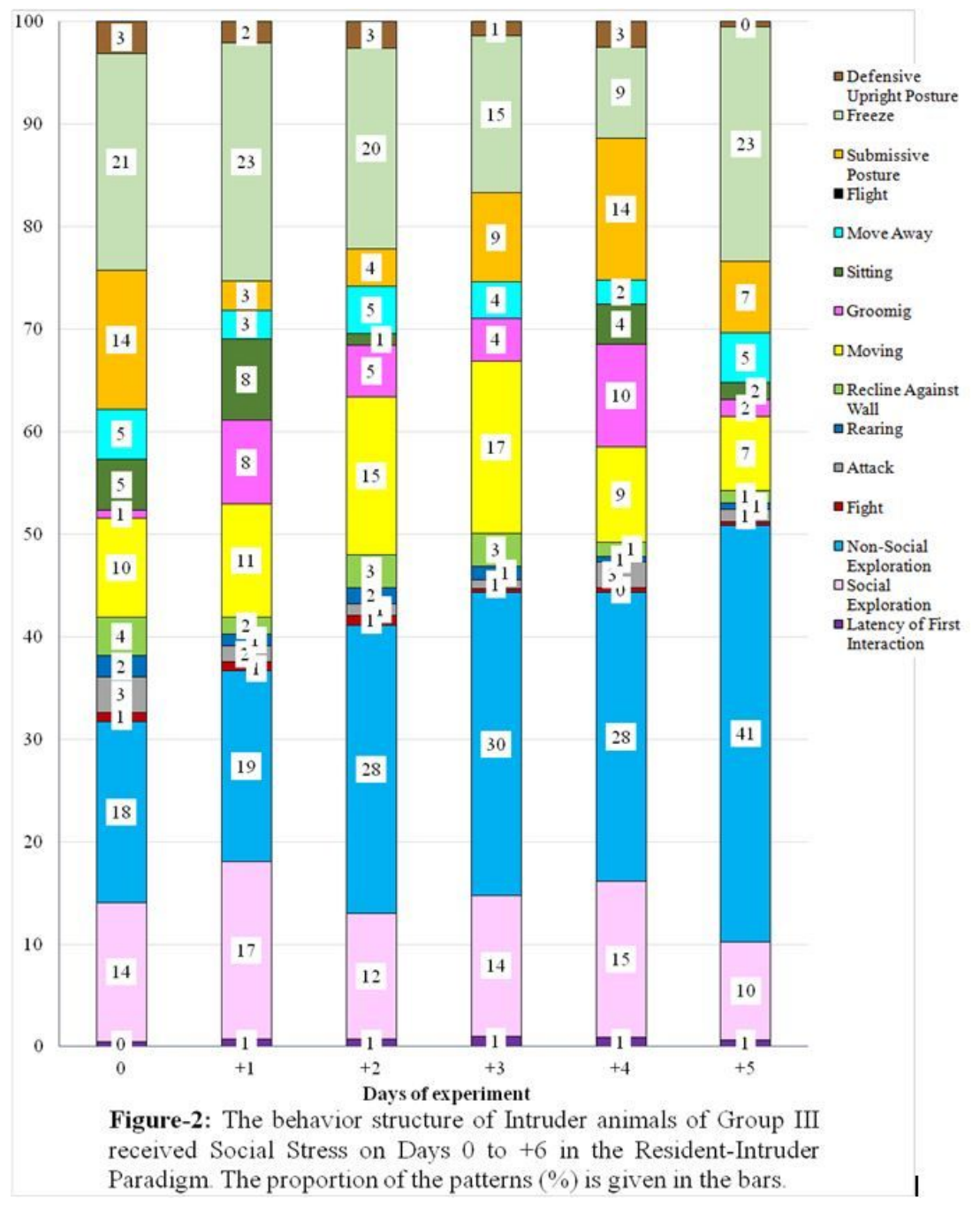

Figure 2 


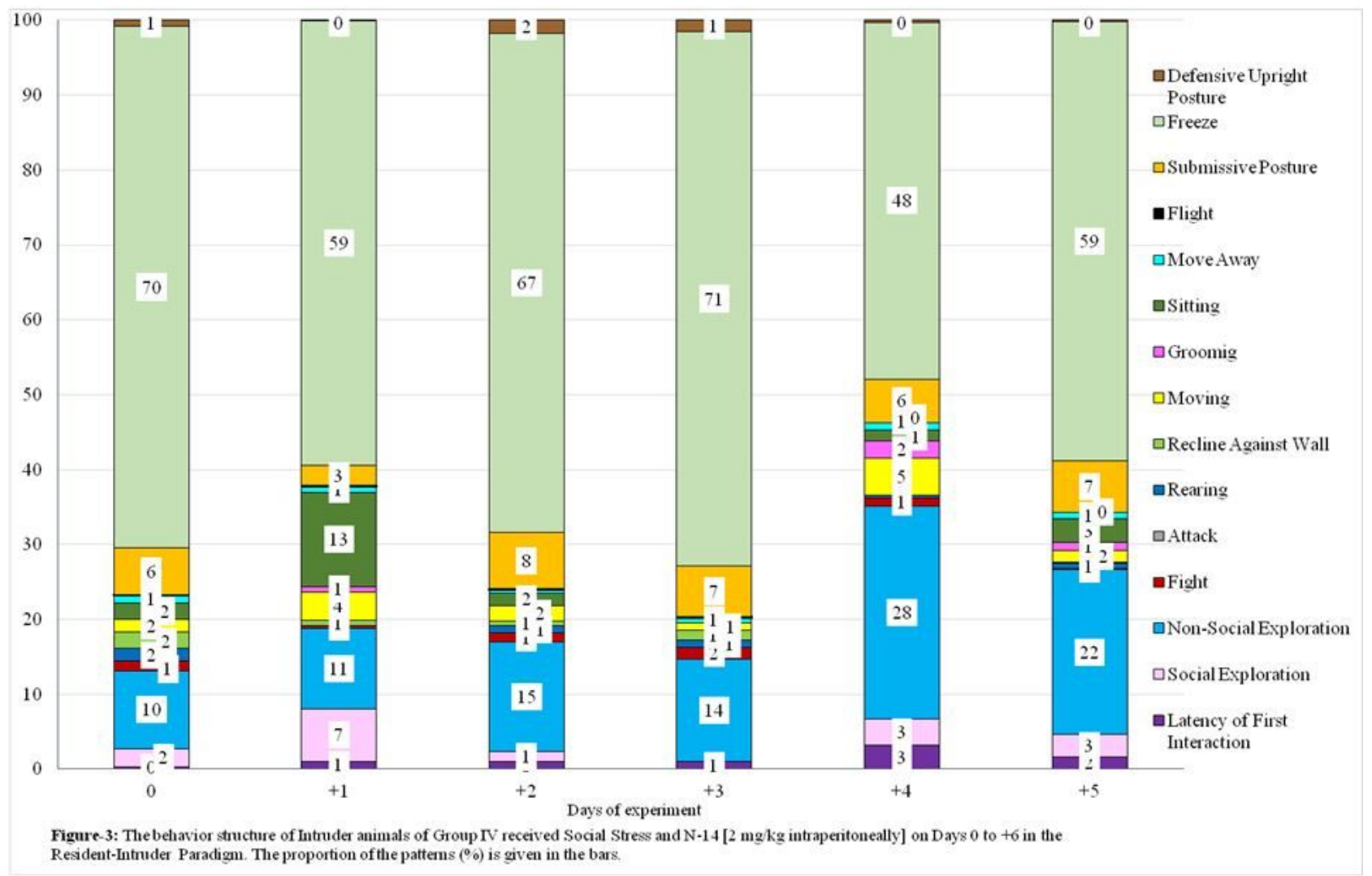

Figure 3

\section{Supplementary Files}

This is a list of supplementary files associated with this preprint. Click to download.

- GaisinaConf.arti.2018Fluoxetine.TranslatedSuppli..pdf

- GaisinaConf.arti2018.FluoxetineUntranslatedSuppli.pdf 